\title{
(2) OPEN ACCESS \\ Rare case of coronary spastic angina during treatment of invasive group A streptococcal sepsis
}

\author{
Tatsuya Sakagami, ${ }^{1}$ Takeshi Tsuji ${ }^{2}$
}

'Department of Emergency, Tokyo Kita Medical Center, Kitaku, Japan

${ }^{2}$ Department of Cardiology, Tokyo Kita Medical Center, Kitaku, Japan

Correspondence to Dr Tatsuya Sakagami; azabu79@yahoo.co.jp

Accepted 8 August 2021

Check for updates

(c) BMJ Publishing Group Limited 2021. Re-use permitted under CC BY-NC. No commercial re-use. See rights and permissions. Published by BMJ.

To cite: Sakagami T, Tsuji T. BMJ Case Rep 2021:14:e244693. doi:10.1136/bcr-2021 244693

\section{SUMMARY}

The underlying mechanisms of coronary spastic angina (CSA) is not well understood. It is unclear if an infection can trigger coronary vasospasm; the co-occurrence of sepsis and CSA has rarely been reported. We describe the case of a 47-year-old man who suddenly developed a complete atrioventricular block and an episode of cardiac arrest while undergoing treatment for sepsis secondary to invasive group A streptococci. Emergency coronary angiography and provocation revealed spasm of the right coronary artery, which had led to the atrioventricular block. The spasm was relieved following administration of calcium-channel blockade, and no subsequent recurrence was documented. Due to several underlying mechanisms, sepsis may be a potential risk factor of coronary spasm and episodes of this condition have been missed or misdiagnosed. Physicians should be aware of CSA as a potential complication during treatment of sepsis.

\section{BACKGROUND}

Generally, stress cardiomyopathy, sepsis-induced cardiomyopathy and myocardial infarction due to mismatch in myocardial oxygen supply and demand (type 2 myocardial infarction) are well-known cardiac events that can occur during the course of sepsis, although a co-occurrence of sepsis and coronary spastic angina (CSA) has not yet been reported.

The prevalence of CSA is not well studied, and is apparently more frequent among Japanese, compared with Caucasian, populations. ${ }^{1}$ The longterm prognosis of patients with CSA is generally good. $^{2}$ However, arrhythmias and myocardial infarction are potentially life-threatening complications of CSA. Administration of calcium-channel blockers is known to reduce the frequency of symptomatic episodes and serious complications. ${ }^{3}$

The mechanisms of CSA are not well known, and it is unclear if infection or sepsis can precipitate coronary spasms. We describe a case of complete atrioventricular block and cardiac arrest, arising from CSA, during treatment of sepsis caused by invasive group A streptococcal infection.

\section{CASE PRESENTATION}

A 47-year-old Japanese man was admitted into the intensive care unit for septic shock and necrotising fasciitis of the axilla. Group A streptococci were detected in both blood and soft tissue cultures. His medical history indicated hypertension, and he was being administered amlodipine, at $5 \mathrm{mg}$ orally once per day, which was discontinued because of hypotension.
Invasive positive-pressure ventilation was performed. Penicillin G (24 million units per day) and norepinephrine $(0.05 \mathrm{mg} / \mathrm{kg}$ per hour $)$ were administered intravenously. Subsequently, serial debridement was performed on his latissimus dorsi from days 1-3 of inpatient care. The treatment response was satisfactory, and intravenous norepinephrine was accordingly tapered.

Despite normal ECG findings on day 1, the patient suddenly developed complete atrioventricular block and subsequently underwent cardiac arrest on day 4 of hospitalisation. Progression of the ECG changes is shown in figure 1A. The ECG revealed changes ranging from normal studies, to Wenckebach-type atrioventricular block, to advanced atrioventricular block, until complete atrioventricular block and cardiac arrest within a few minutes of each determination. Cardiopulmonary resuscitation was immediately commenced, and return of spontaneous circulation (ROSC) was achieved following intravenous administration of $1 \mathrm{mg}$ of epinephrine.

Following ROSC, electrocardiography revealed inverted $\mathrm{T}$ waves on leads $\mathrm{I}, \mathrm{aVL}$ and precordial leads $\mathrm{V}_{5}$ and $\mathrm{V}_{6}$. Subsequently, ST depression was documented on leads I, aVL and precordial leads $\mathrm{V}_{1}-\mathrm{V}_{6}$, along with first-degree atrioventricular block (figure 1B). Echocardiography revealed hypokinesia of the inferior wall. Blood tests revealed no electrolyte imbalances.

Temporary pacemaker insertion and coronary angiography (CAG) were performed on an urgent basis. Since there was no significant stenosis in the coronary arteries, CSA was suspected. Provocative testing with $50 \mu \mathrm{g}$ of ergonovine was selectively performed on the right coronary artery following CAG. Coronary spasm with ST segment elevation in leadsII, III and aVF, and atrioventricular block was confirmed (figure 2A-D). Intracoronary administration of isosorbide nitrate $(5 \mathrm{mg})$ relieved the spasm, and the electrocardiography returned to normal (figure 1C). Further, provocative testing on the left coronary artery was not performed because of risk for haemodynamic instability.

At that time, the possibility was entertained that when the patient underwent cardiac arrest, multiple branches including the left coronary artery may have undergone vasoconstriction, which partially masked the ST segment elevation on initial monitored ECG (figure 1A). To be specific, when the patient underwent arrest, ST segment elevation in leadsII, III and aVF and atrioventricular block manifested due to the spasm of the right coronary artery as was the case on provocation with ergonovine on the right coronary artery. However, due to the 


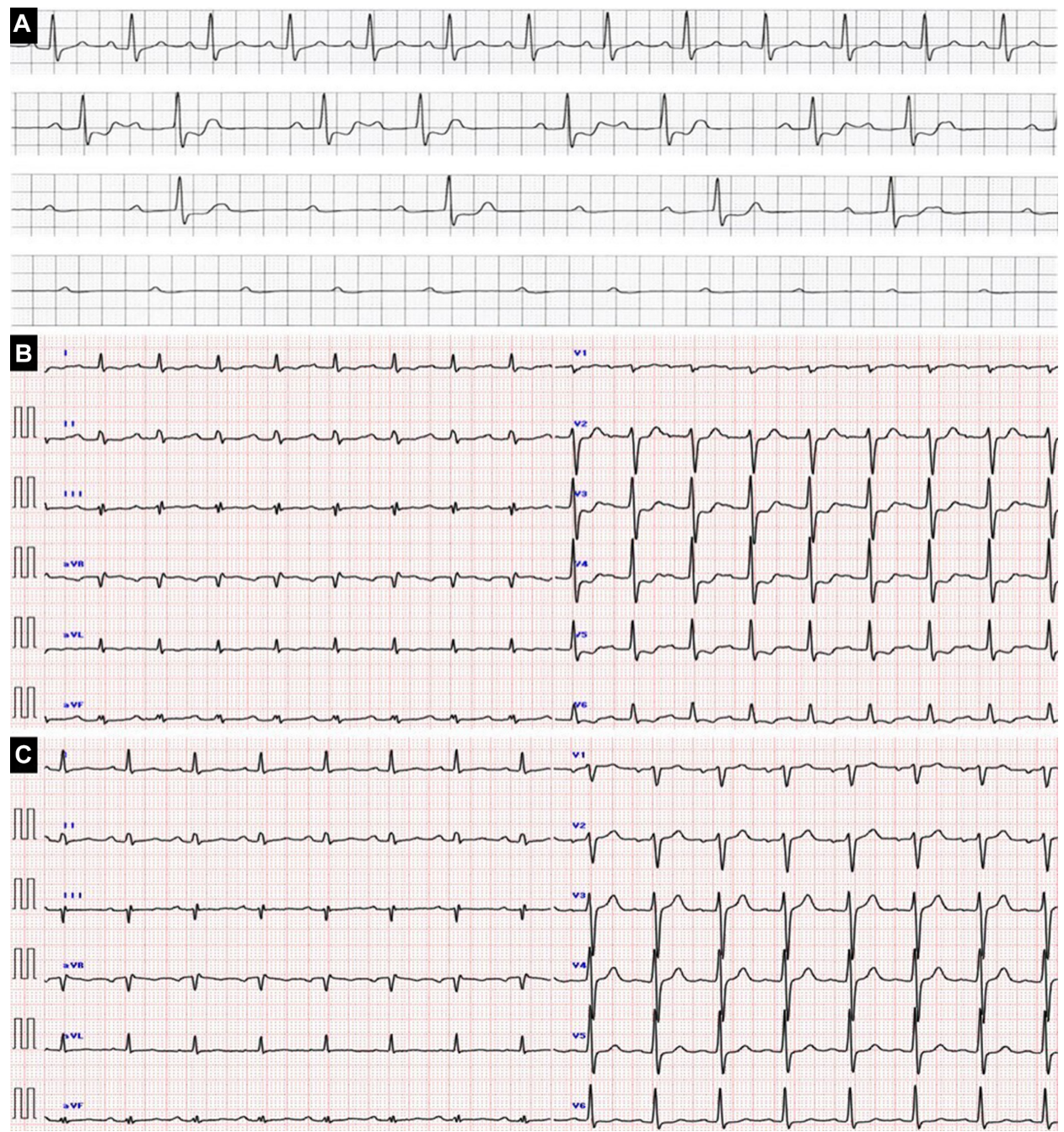

Figure 1 ECG findings. (A) Progress of ECG (24-hour monitoring ECG) : normal $\rightarrow$ Wenckebach-type atrioventricular block $\rightarrow$ advanced atrioventricular block $\rightarrow$ complete atrioventricular block and cardiac arrest. (B) Immediately after ROSC. (C) After CAG. CAG, coronary angiography; ROSC, return of spontaneous circulation.

contralateral ST segment elevation caused by the spasm of the left coronary artery occurring at the same time, the ST changes may have consequently been offset and only the atrioventricular block was observed on initial ECG.

Accordingly, the patient was diagnosed with CSA which had caused complete atrioventricular block and cardiac arrest. A calcium-channel blocking agent (nifedipine, $40 \mathrm{mg}$ per day) was administered to prevent spasms.

\section{OUTCOME AND FOLLOW-UP}

Following calcium-channel blockade, there was no recurrence of coronary spasm or atrioventricular block. Temporary pacing was discontinued on day 6 from admission. Negative blood culture was confirmed and the patient was extubated on day 9 . The patient was transferred from the intensive care unit to the general ward on day 10 . The patient was finally discharged on day 49. There were no further complaints of chest pain, and no changes were observed on cardiac monitoring during hospitalisation. Nifedipine was sufficiently effective in preventing spasm. Furthermore, since atrioventricular block and bradycardia were consistently absent on electrocardiography over a period of more than 1 month of admission, atrioventricular block was deemed to be transient and due to spasm. Therefore, an implantable loop recorder was not inserted. The latest follow-up, at 3 months, indicated no recurrence of symptoms.

\section{DISCUSSION}

The common triggers for coronary spasm include smoking, ${ }^{4}$ drinking, ${ }^{3}$ abnormal lipid or glucose metabolism, ${ }^{5}$ abnormal autonomic nervous function, ${ }^{6}$ use of catecholamines ${ }^{7}$ and hyperventilation. ${ }^{9}$ To our knowledge, this is the first reported case of sepsis and CSA occurring concurrently in a single patient.

This case suggests that sepsis and treatment therefor are potential risk factors for coronary spasm. Failure to diagnose, or misdiagnosis of, coronary spasm may occur during treatment for sepsis.

First, causes of spasms such as hyperventilation, use of catecholamines, discontinuation of calcium-channel blockade and others are likely to occur during the treatment for sepsis. In our case, the discontinuation of amlodipine and intravenous administration of norepinephrine, both due to septic shock and resulting hypotension, could have caused the coronary spasm.

Second, the adverse cardiac event may have occurred due to the more direct effects of sepsis on the blood vessels. Kugiyama et al reported that vascular endothelial dysfunction causes coronary spasm. ${ }^{10}$ Sepsis is a typical condition that causes vascular 

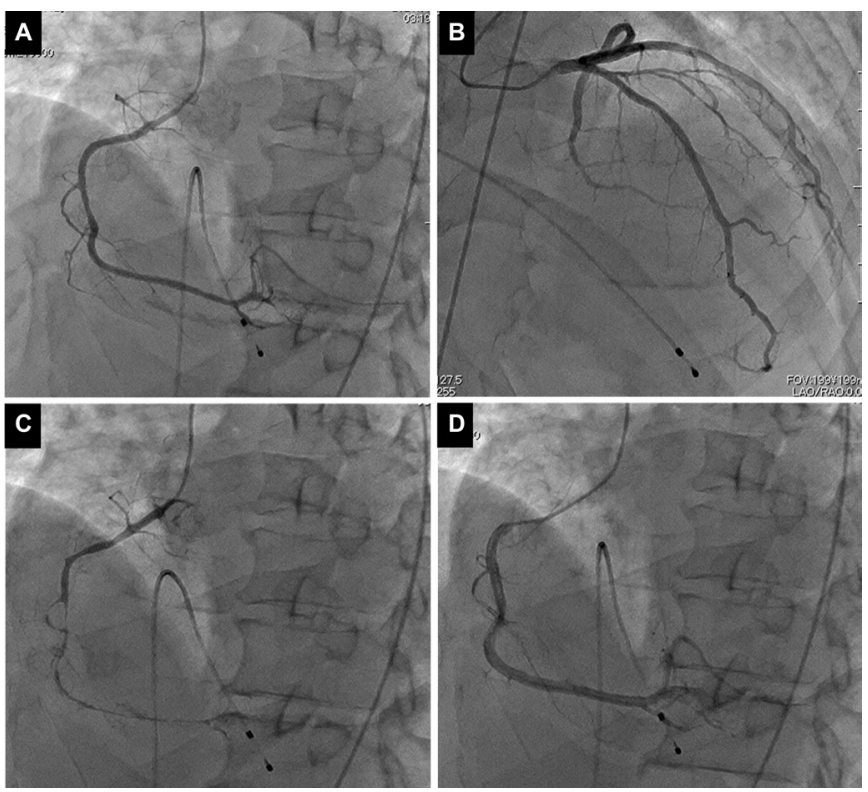

Figure 2 Coronary angiography and provocative testing via ergonovine findings. (A) No significant stenosis observed on CAG (right coronary artery). (B) No significant stenosis observed on CAG (left coronary artery). (C) Provocative testing via ergonovine $(50 \mu \mathrm{g})$ for right coronary artery: positive. (D) Intracoronary administration of isosorbide nitrate $(5 \mathrm{mg})$ relieved the spasm. CAG, coronary angiography.

endothelial injury and inflammation. Moreover, Shimokawa et al reported that blood vessel inflammation leads to coronary spasm and that the mechanism involves hypercontraction from an increase in the Rho-kinase system of vascular smooth muscle cells. ${ }^{11}$ It has been shown that an increase in Rho-kinase occurs in the lungs of patients who underwent septic shock, ${ }^{12}$ which may cause acute respiratory distress syndrome (ARDS); it is possible that this occurs in the heart of a patient with sepsis, which poses risk of coronary angina. Similar to the delay between the onset of sepsis and that of ARDS, it is possible that the attack of spasm on day 4 following treatment of sepsis represents peak likelihood of vasospasm in this case.

Third, the onset and diagnosis of coronary spasm is difficult to ascertain. Patients with sepsis are often intubated or sedated; therefore, they cannot complain of chest pain as expected of coronary spasm. Consequently, physicians may not notice the adverse cardiac event until serious complications, such as haemodynamic instability or cardiac arrest, occur. Moreover, in a state of sepsis, even if physicians notice small changes on the ECG, elevation of cardiac markers or hypokinesia of cardiac wall motion, CAG (much less spasm provocative tests) tends to be avoided due to heightened periprocedural risk and the difficulty of moving the patient and performing the test. As a result, these symptoms could be tentatively diagnosed as stress or sepsis-induced cardiomyopathy or type 2 myocardial infarction. Therefore, it is possible that many CSA events may be misdiagnosed as any of these conditions.

These three factors mentioned are not specific to sepsis; however, sepsis is representative of a condition in which these

\section{Learning points}

- The mechanisms or triggers for coronary spastic angina (CSA) are not well understood.

- Sepsis is a potential high-risk condition that may precipitate coronary spasm; failure in diagnosis and misdiagnosis of CSA may occur with sepsis, as with other conditions.

- Physicians should suspect CSA as a potential complication in case of cardiac events that occur during the treatment of sepsis.

factors tend to occur simultaneously. Therefore, physicians should be aware of CSA if any cardiac events are observed during the treatment of sepsis.

Acknowledgements The authors thank Rei Fukumoto and Tetsuo Yamada who helped in managing the case.

Contributors TS managed the case and drafted the manuscript. TT managed the case and revised the manuscript.

Funding The authors have not declared a specific grant for this research from any funding agency in the public, commercial or not-for-profit sectors.

Competing interests None declared.

Patient consent for publication Obtained.

Provenance and peer review Not commissioned; externally peer reviewed.

Open access This is an open access article distributed in accordance with the Creative Commons Attribution Non Commercial (CC BY-NC 4.0) license, which permits others to distribute, remix, adapt, build upon this work non-commercially, and license their derivative works on different terms, provided the original work is properly cited and the use is non-commercial. See: http://creativecommons.org/ licenses/by-nc/4.0/.

\section{REFERENCES}

1 Kusama Y, Kodani E, Nakagomi A, et al. Variant angina and coronary artery spasm: the clinical spectrum, pathophysiology, and management. J Nippon Med Sch 2011;78:4-12

2 Bory M, Pierron F, Panagides D, et al. Coronary artery spasm in patients with normal or near normal coronary arteries. long-term follow-up of 277 patients. Eur Heart $J$ 1996;17:1015-21.

3 Yasue $H$, Takizawa A, Nagao $M$, et al. Long-Term prognosis for patients with variant angina and influential factors. Circulation 1988;78:1-9.

4 Sugiishi M, Takatsu F. Cigarette smoking is a major risk factor for coronary spasm. Circulation 1993;87:76-9

5 Shimabukuro M, Shinzato T, Higa S, et al. Enhanced insulin response relates to acetylcholine-induced vasoconstriction in vasospastic angina. J Am Coll Cardiol 1995;25:356-61.

6 Yasue $\mathrm{H}$, Touyama M, Shimamoto M, et al. Role of autonomic nervous system in the pathogenesis of Prinzmetal's variant form of angina. Circulation 1974;50:534-9.

7 Qarajeh R, Singh A, Khariton Y, et al. Recurrent ST elevation myocardial infarction from norepinephrine-induced coronary vasospasm. Cureus 2020;12:e7605.

8 Crea F, Chierchia S, Kaski JC, et al. Provocation of coronary spasm by dopamine in patients with active variant angina pectoris. Circulation 1986;74:262-9.

9 Fujii $\mathrm{H}$, Yasue $\mathrm{H}$, Okumura $\mathrm{K}$, et al. Hyperventilation-induced simultaneous multivessel coronary spasm in patients with variant angina: an echocardiographic and arteriographic study. J Am Coll Cardiol 1988;12:1184-92.

10 Kugiyama K, Yasue H, Okumura K, et al. Nitric oxide activity is deficient in spasm arteries of patients with coronary spastic angina. Circulation 1996;94:266-72.

11 Shimokawa H, Seto M, Katsumata N, et al. Rho-Kinase-Mediated pathway induces enhanced myosin light chain phosphorylations in a swine model of coronary artery spasm. Cardiovasc Res 1999;43:1029-39.

12 Cinel I, Ark M, Dellinger P, et al. Involvement of Rho kinase (ROCK) in sepsis-induced acute lung injury. J Thorac Dis 2012;4:30-9. 
Copyright 2021 BMJ Publishing Group. All rights reserved. For permission to reuse any of this content visit https://www.bmj.com/company/products-services/rights-and-licensing/permissions/

BMJ Case Report Fellows may re-use this article for personal use and teaching without any further permission.

Become a Fellow of BMJ Case Reports today and you can:

- Submit as many cases as you like

- Enjoy fast sympathetic peer review and rapid publication of accepted articles

Access all the published articles

- Re-use any of the published material for personal use and teaching without further permission

Customer Service

If you have any further queries about your subscription, please contact our customer services team on +44 (0) 2071111105 or via email at support@bmj.com.

Visit casereports.bmj.com for more articles like this and to become a Fellow 